\title{
Failure mechanism of shear-wall dominant multi-story buildings
}

\author{
S. B. Yuksel ${ }^{1} \&$ E. Kalkan ${ }^{2}$ \\ ${ }^{I}$ Department of Civil Engineering, Selcuk University, Turkey \\ ${ }^{2}$ California Geological Survey, Sacramento, CA, USA
}

\begin{abstract}
The recent trend in the building industry of Turkey as well as in many European countries is towards utilizing the tunnel form (shear-wall dominant) construction system for development of multi-story residential units. The tunnel form buildings diverge from other conventional reinforced concrete (RC) buildings due to the lack of beams and columns in their structural integrity. The vertical load-carrying members of these buildings are the structural-walls only, and the floor system is a flat plate. Besides the constructive advantages, tunnel form buildings provide superior seismic performance compared to conventional RC frame and dual systems as observed during the recent devastating earthquakes in Turkey (1999 $\mathrm{M}_{\mathrm{w}}$ 7.4 Kocaeli, $\mathrm{M}_{\mathrm{w}}$ 7.2 Duzce, and $2004 \mathrm{M}_{\mathrm{w}} 6.5$ Bingol). With its proven earthquake performance, the tunnel form system is becoming the primary construction technique in many seismically active regions. In this study, a series of nonlinear analyses were conducted using finite element (FE) models to augment our understanding on their failure mechanism under lateral forces. In order to represent the nonlinear behavior adequately, The FE models were verified with the results of experimental studies performed on three dimensional (3D) scaled tunnel form building specimens. The results of this study indicate that the structural walls of tunnel form buildings may exhibit brittle flexural failure under lateral loading, if they are not properly reinforced. The global tension/compression couple triggers this failure mechanism by creating pure axial tension in the outermost shear-walls.
\end{abstract}

Keywords: nonlinear analysis, tunnel form building, reinforced concrete, shearwall, cyclic loading, finite element. 


\section{Introduction}

The tunnel form system is an industrialized construction technique, in which structural walls and slabs are cast in a single operation. A typical tunnel form system and its site applications are demonstrated in fig. 1. Tunnel form buildings diverge from other conventional reinforced concrete structures due to the lack of beams and columns in their structural integrity. All the vertical members are made of shear-walls and the floor system is a flat plate. These structures utilize all wall elements as the primary load (wind and seismic as well as gravity) carrying members and vertical and lateral loads are distributed homogeneously to the foundation.
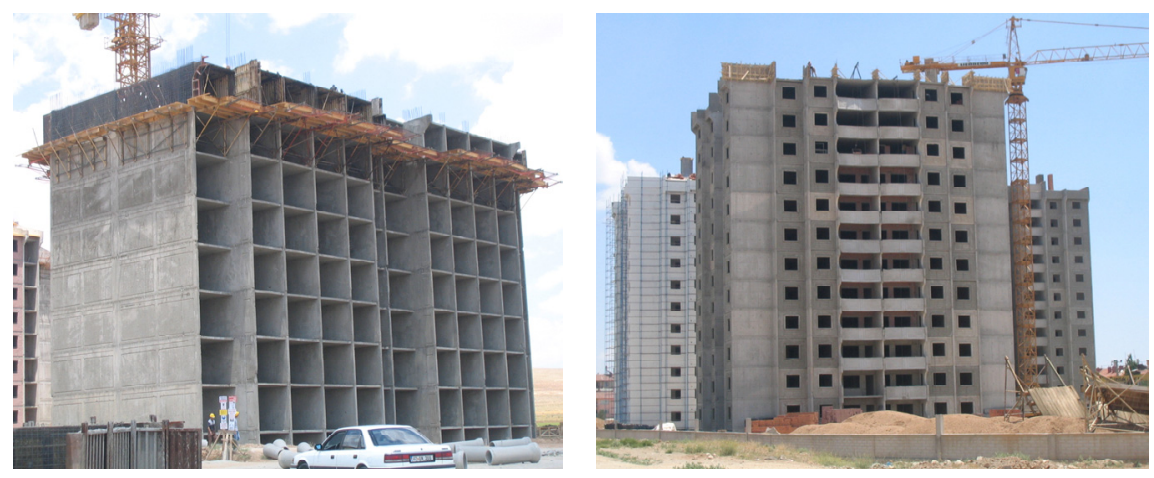

Figure 1: Typical tunnel form buildings in the construction stages.

The simultaneous casting of walls, slabs and cross-walls results in a monolithic structure with a horizontal and vertical continuity. This essentially warrants a high seismic performance. This construction technology provides great advantages over conventional construction systems, by eliminating the use of scaffolding, plastering and simplifying certain operations of the placement and striking of formwork as well as the installation of reinforcements. The system as a whole allows for better organization of the construction activities enabling a continuous flow of work, and a higher quality standard. With these features, not only in Turkey, but also in many other countries prone to seismic risk, tunnel form buildings are gaining increasing popularity [1].

Despite their frequent application, there is a lack of experimental studies to understand the $3 \mathrm{D}$ response of tunnel form buildings under extreme lateral loading conditions. Previous experimental studies conducted on shear-wall systems were generally limited to two-dimensional (2D) investigations. However, it was analytically proven that the $2 \mathrm{D}$ approach is not adequate to capture the important behavior of tunnel form buildings under seismic action due to significant slab-wall interaction and global tension-compression (T/C) coupling effects [2-4]. In addition, modern design guidelines for traditional RC buildings $[5,6]$ are not adequate to account for interactions of thinner shear-wall and slab configurations as the common components of the tunnel form system. 
In this study, 3D experimental work and numerical investigations on the seismic behavior of tunnel form buildings are presented. Two four-story scaled building specimens were tested under quasi-static lateral loading in longitudinal and transverse directions. The experimental results and supplemental finite element simulations collectively indicate that lightly reinforced structural walls of tunnel form buildings may exhibit brittle flexural failure under seismic action.

\section{Details of test specimens and experimental procedure}

The experimental work described herein involves the testing of two four-story 1/5-scale RC tunnel form building test specimens as shown in fig. 2. The specimens are the representatives of a typical tunnel form section in a regular tunnel form building. Both specimens had identical dimensions, reinforcement detailing and material properties. The testing program consisted of lateral cyclic loading. The specimen tested along its weak axis is referred to as SP1, and the other specimen tested along its strong axis is called SP2 (see fig. 3).

Both specimens were monolithically constructed at each floor level similar to standard applications. They were manufactured on the same foundation and clamped to the strong floor by high-strength steel bolts. It should be noted that the walls in the longitudinal direction are referred to as flange walls and the walls in the short direction are referred to as web walls. The amount of reinforcement used in the walls corresponded to the minimum vertical and horizontal reinforcement ratio (i.e. the ratio of reinforcement area to gross concrete area) requirement $\left(\rho_{s v}, \rho_{s h}=0.0015\right)$ of the regulatory seismic design code in Turkey [6]. Mesh reinforcement for the walls consisted of $2 \mathrm{~mm}$ diameter plain bars. It should also be noted that the mesh reinforcement used in the shear-walls of tunnel form buildings has relatively small diameter bars (5.0 $\mathrm{mm}, 5.5 \mathrm{~mm}$, etc.) compared to that used in conventional shear-walls of RC buildings.

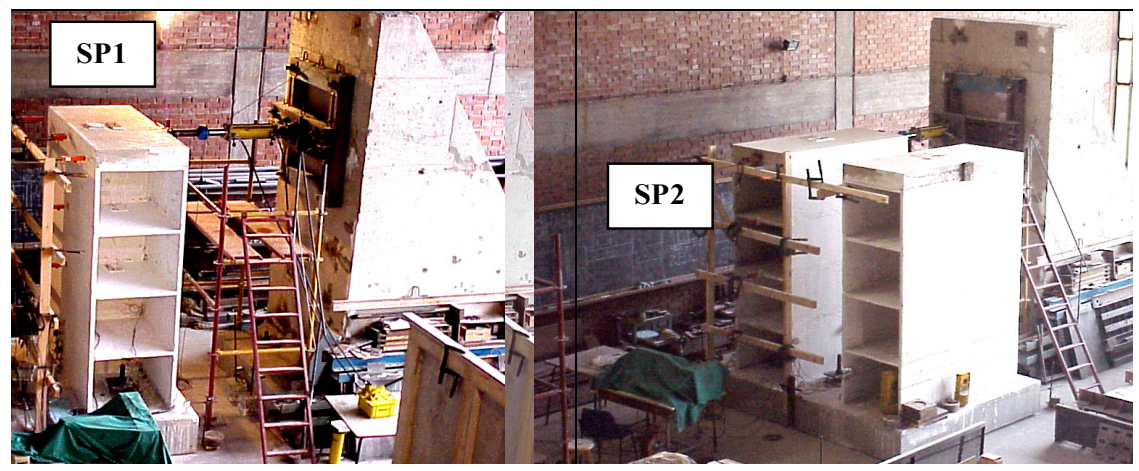

Figure 2: $\quad$ Test setup, loading system and instrumentation (SP1 (loading along weak axis) and SP2 (loading along strong axis)). 
As shown in fig. 3, the single-layer mesh reinforcement was placed in the middle of the walls. The bar spacing in the vertical and horizontal directions was kept $50 \mathrm{~mm}$. The wall reinforcement was spliced at floor levels with a splice length of 50 bar diameters $(100 \mathrm{~mm})$. In the slabs, a $2.5 \mathrm{~mm}$ diameter singlelayer mesh reinforcement located in the middle of the section was used at a spacing of $50 \mathrm{~mm}$ in both horizontal directions. As opposed to the wall reinforcement ratio, the ratio of slab reinforcement along each orthogonal direction was 0.0025 . The material properties of reinforcing steel are provided in fig. 4. The concrete strength of the test specimens was $35 \mathrm{MPa}$ on the day of testing. The ultimate strength values of reinforcement and concrete used in the test specimens are in compliance with those used in practice.

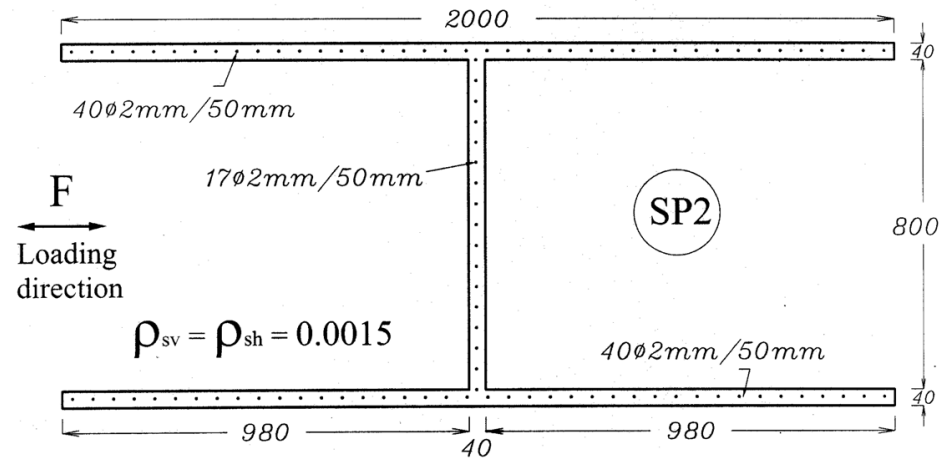

Figure 3: Reinforcement detailing of the shear-walls of the SP2, units are in $m m$.

\section{3D nonlinear finite element modeling}

The behavior of test specimens under lateral loading was numerically simulated through 3D nonlinear finite element models created using the general-purpose finite element program, DIANA [7]. The specimens of the walls and slabs were modeled using eight-node brick elements. A $4 \times 4$ gauss integration scheme in more than 13000 elements was used. In finite element models, the governing nonlinear phenomena in the ultimate limit state were cracking and crushing of concrete and the plastic behavior of reinforcement steel. The finite element models allowed the evaluation of stress and deformations more comprehensively within a parametric framework; thereby a better understanding of the behavior of specimens during loading to failure was achieved.

The applied analysis procedure was based on the total strain cracking model (cracks have opening/closing and rotating capabilities) using the secant-stiffness approach. The behavior of concrete was idealized using a constitutive model based on nonlinear fracture mechanics. A crack model, having opening/closing and rotating capabilities based on the coaxial stress-strain concept, whereby the stress-strain relationships were evaluated in the principal directions of the strain 
vector, was employed. The compression behavior of concrete was modeled using the unconfined concrete model proposed by Popovics [8] and modified by Thorenfeldt et al. [9]. The tension stiffening of concrete was considered as linear ascending curve up to cracking limit, and the tension softening portion of the stress-strain curve was based on the model proposed by Hordijk [10], which utilizes mode- $I$ fracture energy $\left(G_{f}\right)$, ultimate tensile strength $\left(f_{t}\right)$ and crack bandwidth $\left(h_{c r}\right)$ to compute the maximum crack opening $\left(w_{u}\right)$. This model results in a crack stress equal to zero at an ultimate crack strain $\left(\varepsilon_{u}{ }^{c r}\right)$. The crack bandwidth was computed based on the finite element mesh dimensions. The approximated concrete stress-strain relationship in compression and tension is shown respectively in figs. $4 \mathrm{a}$ and $4 \mathrm{~b}$. The constant shear retention factor $(\beta$ factor), to account for the degradation in the shear stiffness after crack initiation (fig. 4c), was utilized as 0.1 based on the verification studies. Poison's ratio for concrete was taken as 0.20 in all analyses. Cracking of the concrete was considered using a constant stress-cutoff criterion, meaning that, once the maximum principal tensile stress reaches the tensile strength, independent of the other principal stresses, a crack is initiated perpendicular to the principal stress. The orientation of the crack is then stored and the material response perpendicular to the crack path is determined based on the stress-strain relation for the cracked material volume [11].

The constitutive behavior of the reinforcing steel was modeled by using the Von-Mises plasticity model with an associated flow law and isotropic strain hardening. The smeared reinforcement model was utilized to simulate the

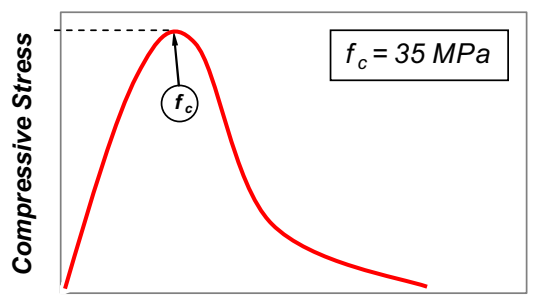

Strain, $\varepsilon_{\mathbf{c}}$

(a) Unconfined concrete model

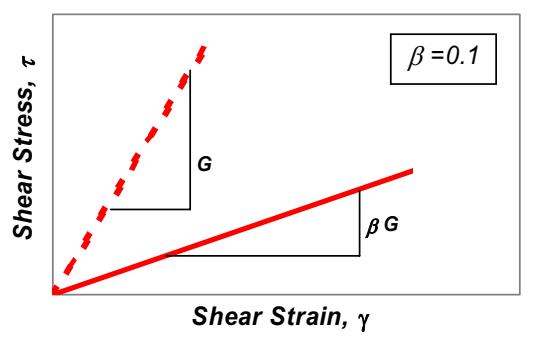

(c) Shear retention

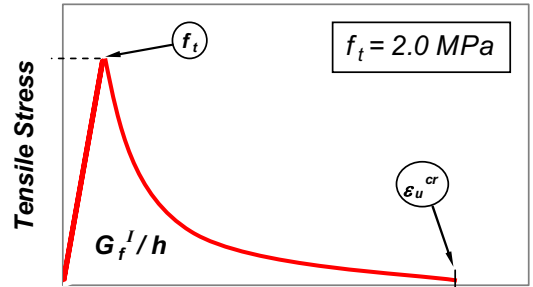

Strain, $\varepsilon_{\mathrm{c}}$

(b) Nonlinear tension softening model

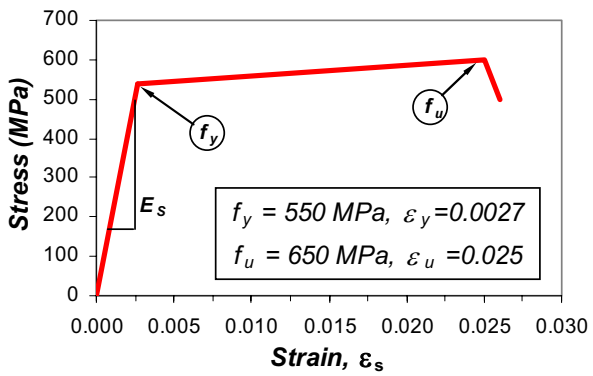

(d) Reinforcement steel model

Figure 4: $\quad$ Concrete and reinforcement steel material models. 
reinforcement mesh. The smeared reinforcement model was treated as an equivalent uniaxial layer of the material at the appropriate depth and smeared out over the element as several orthotropic layers. Transferring the strength and stiffness of the reinforcement directly into the concrete elements, this model is the easiest to implement particularly for the modeling of mesh-reinforcement [12]. Stress-strain behavior of the steel was modeled using a bilinear relationship. The parameters of models were calibrated to test data provided by Yuksel and Kalkan [13]. The material properties and stress-strain relationship for reinforcing steel are presented in fig. $4 \mathrm{~d}$.

\section{Nonlinear static pushover analyses}

The experimental data reported in Yuksel and Kalkan [13] was used for verification of simulated inelastic behavior. Nonlinear static pushover analyses were applied whereby the finite element models were pushed laterally with incrementally increasing lateral displacement from the roof level. Displacement control analyses were conducted in two horizontal directions separately (corresponding to similar loading directions of the test specimens) while the gravity load was kept sustained.

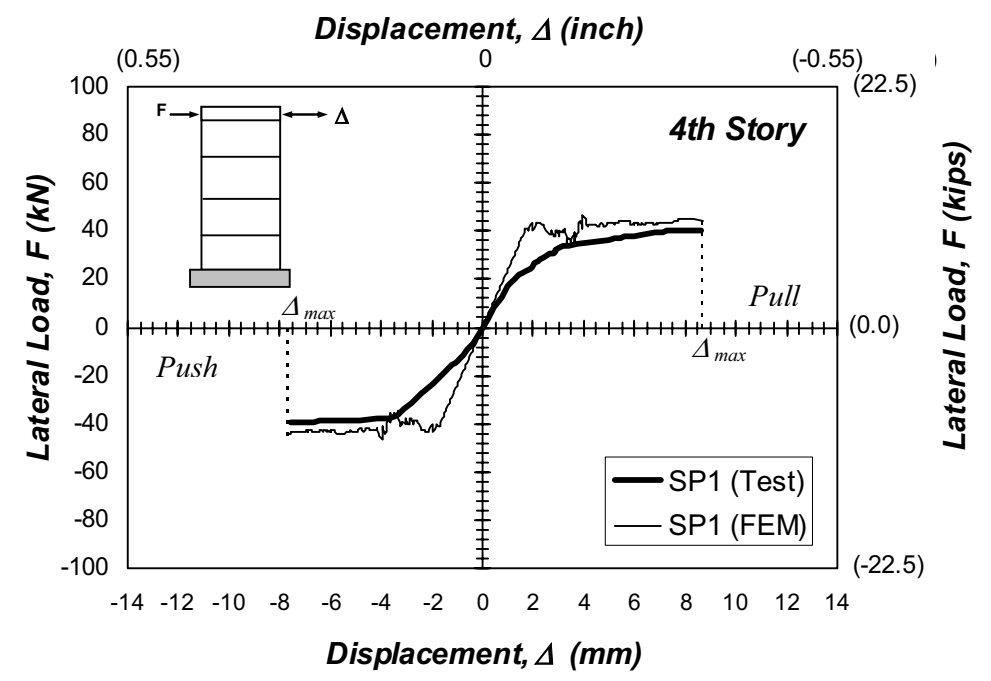

Figure 5: Computed capacity curve and experimental cyclic envelope curves of SP1.

Based on the analyses, load-deflection curves were obtained for both specimens and compared to envelope curves produced from experimental results in fig. 5 and fig. 6 . The envelope curves contain the maximum loads at each displacement level. Experimentally obtained plots show that the lateral load carrying capacity of SP2 (loaded along the strong-axis) is two times larger than that of SP1 (loaded along the weak-axis). Conversely, SP1 provided maximum 
lateral displacement two times larger than that of SP2. Compared to experimental results, the computed response of FE models is somewhat stiffer and stronger. Some of the discrepancy can be attributed to complex threedimensional behavior and primarily the difference between monotonically increasing loading and cyclic loading, but some is also due to modeling assumptions. Despite these discrepancies, comparison of results reveals that the analytical models reasonably captured the salient response characteristics of the test specimens.

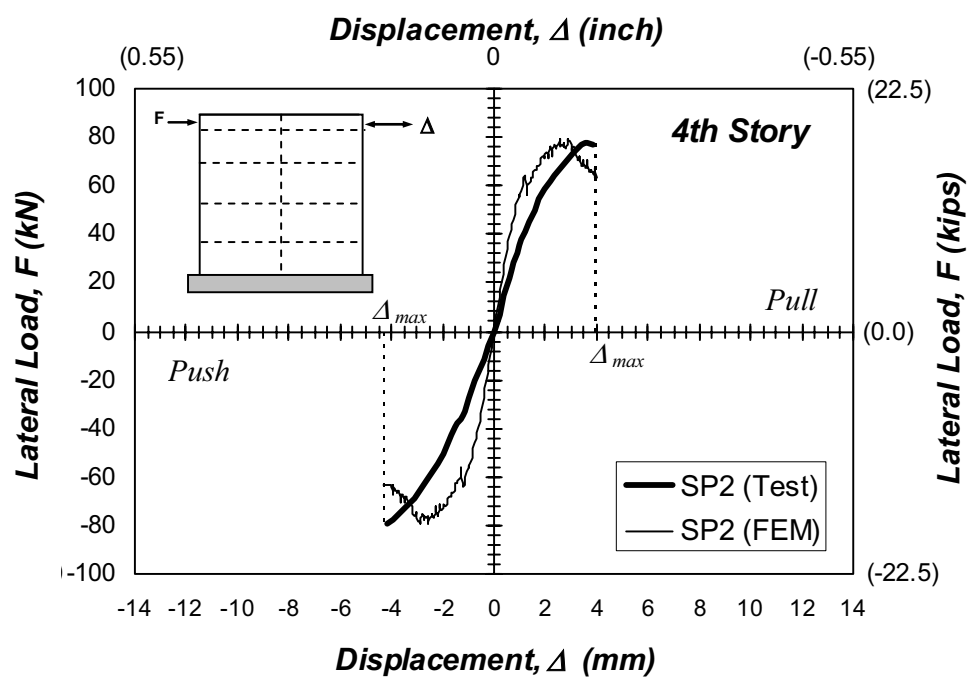

Figure 6: Computed capacity curve and experimental cyclic envelope curves of SP2.

\section{Finite element models for reversed cyclic lateral loadings}

In this part of the study, FE models were re-analyzed under similar cyclic loading conditions applied to test specimens (SP1 and SP2). Among different iteration schemes (e.g., Newton-Raphson) the BFGS (Broyden-FletcherGoldfarb-Shanno) scant stiffness method [14] was found to be more stable to achieve the convergence criterion specified as energy norm at each increment (an energy tolerance of $0.01 \%$ was used). The cracking patterns and the load versus deflection curves shown in figs. 7 and 8 were used to determine the capabilities of the analytical models to replicate the observed 3D behavior. The results of FE analyses generally corresponded reasonably with the results of experiments; load versus displacement curves of the analytical study adequately overlapped the experimental results, and the cracking patterns obtained were also well captured at the maximum load level. The models were found numerically stable. Despite some discrepancies, the overall good correlation between the experimental findings and numerical results enhanced the reliability of the analytical models. 


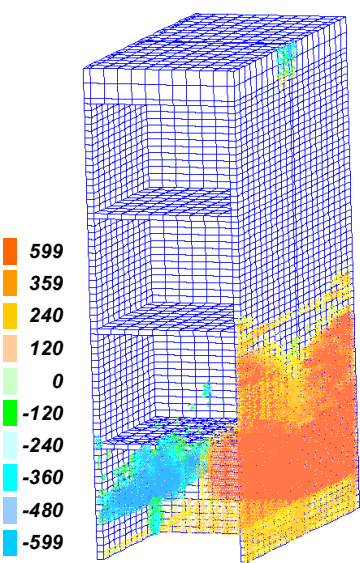

(a)

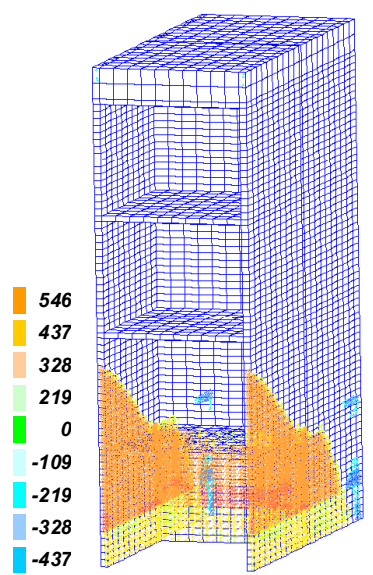

(b)



(c)

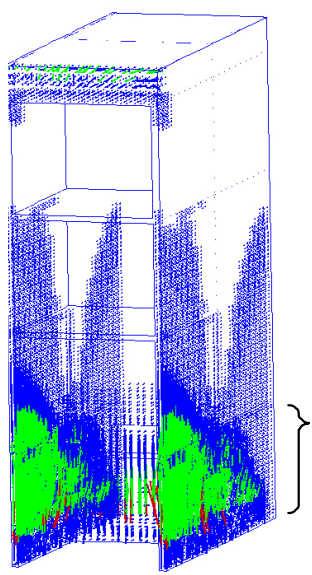

(d)
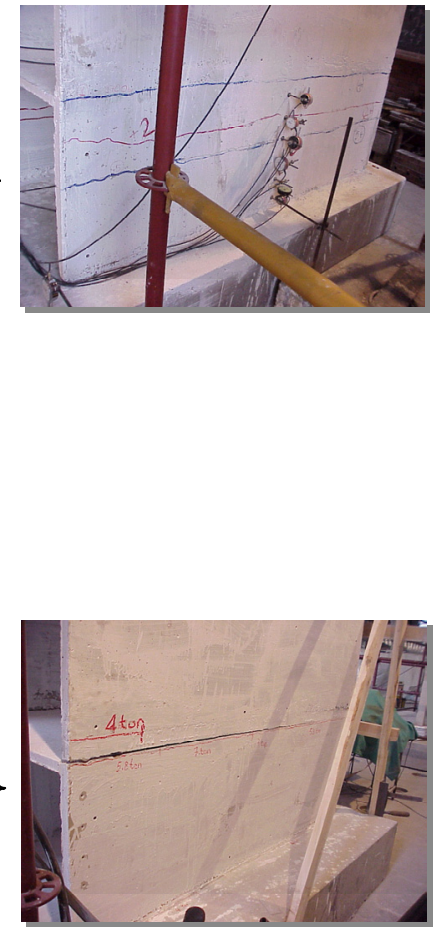

Figure 7: $\quad(\mathrm{a}, \mathrm{b})$ Stress concentration on longitudinal bars at failure (Note: Yield strength of steel is $540 \mathrm{MPa}$, negative sign indicates compression), (c,d) Comparison of computed and experimental damage patterns.

For specimens SP1 and SP2, the mode of the failure was brittle. The crushing of concrete was not observed and the damage was concentrated on the shearwalls only. This failure mechanism occurred due to the low longitudinal reinforcement ratio of the walls and the negative contribution of the low axial load, the section cracked as a consequence of tensile forces acting in the opposite direction of the axial load. In other words, the low axial load has a lower contribution to retarding the tensile stress initiation. As soon as the tensile stress in the concrete exceeded the modulus of rupture (tensile strength), the cracking took place and the concrete immediately released the tensile force it carried. Then, the lightly stressed steel absorbed this increment of the load. For both 
specimens, the minimum amount of longitudinal steel was unable to carry the additional load, therefore following the cracking of concrete, the longitudinal reinforcements yielded and ruptured suddenly without warning. The damage in SP2 was concentrated in the first-story slab wall connection, potentially a zone of weakness due to the construction joint.
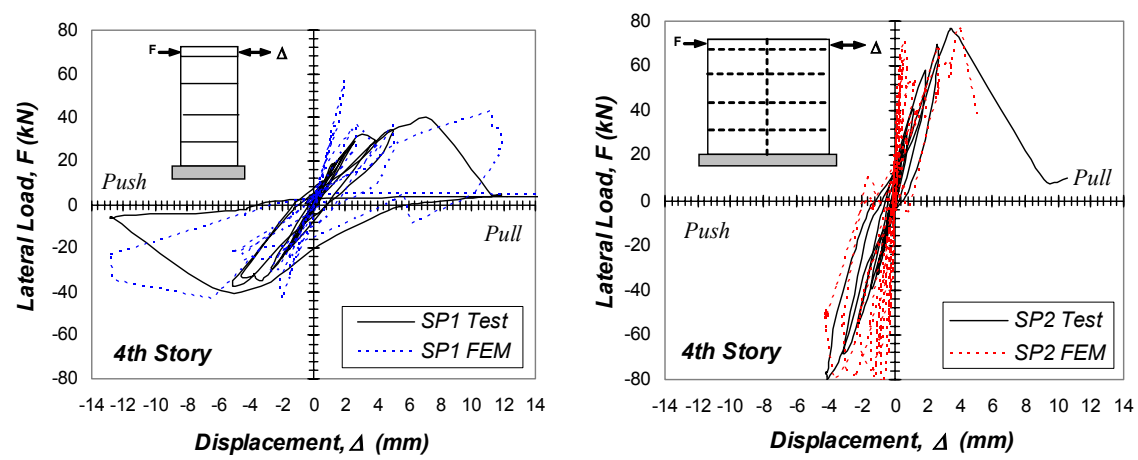

Figure 8: Comparison of computed finite element method (FEM) and experimental (test) cyclic response curves.

FE models provide approximately similar cracking patterns observed in the experiments as depicted in fig. 7. Figs $7 \mathrm{a}$ and $7 \mathrm{~b}$ clearly manifest the high stress concentration when the model is loaded along its weak axis (as in SP1) and the yielding of longitudinal reinforcement as well as the mobilization of horizontal cracking above the mid-height of the first story flanges of SP1. Similar to experimental observations, diagonal cracking occurred on the web wall in the analytical model. The loading of the FE model along the strong axis (as in SP2) resulted in a reasonably similar damage pattern being observed experimentally. To be more specific, the yielding of steel (fig. 7c) and cracking of concrete concentrated in the first story slab wall connection joint (fig. 7d). These comparisons show the capability of the computer models.

\section{Conclusions}

The construction technique of tunnel form buildings and functional considerations may require shear-wall dimensions to be set much larger than those required for flexural strength or for deflection control. Because of the large lever arm between the components of the internal couple, a wall section of this type may require a very small reinforcement area. As a result, its nominal flexural strength may be less than the cracking moment of the cross section. If the cracking moment in a wall section of this type is ever exceeded, e.g. by seismic overload, the wall may fail immediately with the rupture of the steel.

The global tension/compression couple triggers this failure mechanism by creating pure axial tension in the outermost shear-walls. This type of failure takes place due to the rupturing of longitudinal reinforcement without crushing 
of the concrete and is therefore of particular interest in emphasizing the mode of failure that is not routinely considered during seismic design of shear-wall dominant structural systems.

\section{References}

[1] Yuksel, S. B., Slit Connected Coupling Beams For Tunnel Form Building Structures. The Structural Design of Tall and Special Buildings, (in press), DOI: $10.1002 /$ tal.367.

[2] Balkaya, C. \& Kalkan, E., Estimation of fundamental periods of shear wall dominant building structures. Earthquake Engineering and Structural Dynamics, 32(7), pp. 985-998, 2003.

[3] Balkaya, C. \& Kalkan, E., Seismic vulnerability, behavior and design of tunnel form buildings. Engineering Structures, 26(14), pp. 2081-2099, 2004.

[4] Balkaya, C. \& Kalkan, E., Three-dimensional effects on openings of laterally loaded pierced shear walls. Journal of Structural Engineering, ASCE, 130(10), pp. 1506-1514, 2004.

[5] ACI 318-07, Building Code Requirements for Reinforced Concrete and Commentary. American Concrete Institute; Farmington Hills, MI., 2007.

[6] TSC 2006, Specifications for the Structures to be Built in Disaster Regions. Ministry of Public Work and Settlement, Ankara, Turkey (Turkish Seismic Code 2006), 2006.

[7] TNO DIANA. TNO Building Construction and Research, Delft The Netherlands, 2004

[8] Popovics, S., A numerical approach to the complete stress-strain curve for concrete. Cem. Concr. Res., 3(5), pp. 583-599, 1973.

[9] Thorenfeldt, E., Tomaszewicz, A. \& Jensen, J.J., Mechanical properties of high strength concrete and application in design. Proc. Symposium Utilization of High Strength Concrete. Stavanger, Norway, June, Tapit, Trondheim, pp. 149-159, 1987.

[10] Hordijk, D.A., Local approach to fatigue of concrete, $\mathrm{PhD}$ thesis, Delft Univ. of Tech., 1991.

[11] Johansson, M., Nonlinear finite-element analyses of concrete frame corners. Journal of Structural Engineering, ASCE, 126(2), pp. 190-199, 2000.

[12] Balkaya, C. \& Kalkan, E., Nonlinear seismic response evaluation of tunnel form building structures. Computers \& Structures, 81(3), pp. 153-165, 2003.

[13] Yuksel, S. B. \& Kalkan, E., Behavior of Tunnel Form Buildings Under Quasi-Static Cyclic Lateral Loading. Structural Engineering \& Mechanics, 27(1), pp. 99-115, 2007.

[14] Kalkan, E. \& Yuksel, S. B., Prons and Cons of Multi-Story RC Tunnel Form Buildings. The Structural Design of Tall and Special Buildings, (in press), DOI: 10.1002/tal.368. 